\title{
Lifestyle advice for infertile men may require overhaul
}

Published online: 18 June 2012

(C) Springer Healthcare 2012

MedWire News: Common modifiable lifestyle choices such as drinking alcohol, smoking tobacco, or using recreational drugs seem to be unrelated to poor sperm quality, suggest UK study findings.

"This potentially overturns much of the current advice given to men about how they might improve their fertility and suggests that many common lifestyle risks may not be as important as we previously thought," said lead author Andrew Povey from the University of Manchester in a press statement.

The team reports that the 939 men with low motility sperm concentration (MSC; $<12 \times 10^{6} / \mathrm{mL}$ progressively motile sperm) were significantly more likely to have undergone testicular surgery, be of Black ethnic origin, be a manual worker, or be unemployed than 1310 men with a healthy MSC, at odds ratios (ORs) 2.39, 1.99, 1.28, and 1.78, respectively.

By contrast, the men with a higher MSC were more likely to wear boxer shorts or have a history of previous conception, at ORs of 0.76 and 0.71 , respectively.

The researchers examined demographic and social factors associated with poor semen quality among 939 men attending 14 UK fertility clinics over 37 months from January 1999.

However, reportedly important and potentially reversible lifestyle factors including smoking, alcohol consumption, the use of recreational drugs (eg steroids or cocaine), and a high body mass index showed no such association with low MSC.

"Our study shows that common lifestyle factor choices, other than wearing tight underwear, make little contribution to MSC," write Povey and colleagues in Human Reproduction.

"Whilst the message of 'no smoking, no drinking, and no street drugs' should be offered as good health advice... delaying assisted conception to make poorly evidenced changes to lifestyle is unlikely to enhance conception and may indeed be prejudicial in couples with little time to lose," they conclude.

By Sally Robertson

Reference

Hum Reprod 2012; Advance online publication 